\title{
The formation and development of the performance assessment method in the conception of operational management
}

Mikhail B. Zuev ${ }^{\mathrm{a}}$

E-mail:m.zuev25@mail.ru

Boris P. Zuev ${ }^{\text {a }}$

E-mail: zuevboria@yandex.ru

\section{Irina N. Bulgakova ${ }^{\mathrm{b}}$}

E-mail: Bulgakova-IN@yandex.ru

${ }^{a}$ Oil Component Ltd.

Address: 8, Heroes of Hassan Street, Perm 614000, Russia

${ }^{\mathrm{b}}$ Voronezh State University

Address: 1, University Square, Voronezh 394006, Russia

\begin{abstract}
This article is devoted to the integrated performance assessment method - an improved version of the earned value management. It provides a description of the key features and benefits of practical application of the performance assessment method to develop estimates and forecasts of activity. It sets out the authors' opinion about the performance assessment method for execution of key performance indicators in a balanced scorecard. The article touches upon the problems of management due to the unsettled terminology among managers, and various interpretations of the terms: efficiency, effectiveness and economy in management, and proposes a definition to align terminology to uniformity. It provides in a graphical way the vector system: efficiency as the resulting vector of activities obtained from multiplying the vectors of productivity and efficiency, orthogonal to the plane of the multiplied vectors. It gives a conceptual model of the organizational structure of management and cooperation of stakeholders, which opens opportunities for the economic growth of the enterprise, its protection from external or internal risks, both managerial and technological.
\end{abstract}


Key words: performance assessment method; efficiency; effectiveness; economy; management; key performance indicator; performance management system.

Citation: Zuev M.B., Zuev B.P., Bulgakova I.N. (2020) The formation and development of the performance assessment method in the conception of operational management. Business Informatics, vol. 14, no 1, pp. 75-84. DOI: 10.17323/2587-814X.2020.1.75.84

\section{Introduction}

$\mathrm{W}$ hen making management decisions, the object of research (management processes) can be divided into two directions, highlighting the processes of strategic and operational management. Strategic management is intended to direct management's impact on ensuring the future competitive superiority of the organization. The operational management process is aimed, in turn, at ensuring the periodic work of the organization to achieve the main objectives.

To assess the effectiveness of management in Russian practice, we most often use economic performance, production indicators, financial and economic indicators taken separately or in combination with each other.

Among the foreign methods of assessing the effectiveness of management, the most popular are:

DuPont model [1];

$\downarrow$ the French concept of efficiency management Tableau De Bord [2], which has been developed in the works of Eve Cheapello and Michel Lebas [3];

$\downarrow$ Lorenz Meisel's model [4], which focuses on staff development;

$\checkmark$ effective progress and performance measurement (EP2M) model developed by Christopher Adams and Peter Roberts [5];

$\downarrow$ business activity control indicators (key performance indicators, KPI) [6];

balanced scorecard system - strategic planning system by R. Kaplan and D.P. Norton [7].

One of the main reasons for the inefficiency of operational management in various production areas is the use of the most popular method of management today - manual, "on the peephole." Management experts stress that better management requires more attention to be paid to the lack of tools to assess effectiveness and quickly monitor what you are doing $[8,9]$. According to PricewaterhouseCoopers, $61 \%$ of Russian representatives note the need to adjust the set of performance management indicators of the company [10].

The transition to technological system management through targeted change requires addressing the problem of the "nontechnological behavior" of participants, both with mandatory planning and implementation of these plans. In order to raise the technological improvement of management, the success of the tasks and the accuracy of the management decisions taken, it is necessary to have a set of tools that make up a real management system, an integral part of which are not only "levers and pedals" but also the ability to measure performance indicators and deviate from plans, or rather, tools to assess and predict the effectiveness of the process and result of performance, new alternative methods of measuring non-financial indicators. The need for such a measurement is explained by the possibility of achieving only a measurable result. 


\section{Theoretical approaches to determining effectiveness}

The results of the management decisionmaking process are ensured by the experience of managers, their competence and skills in the use of modern methods and tools to achieve the desired goal, as well as a mandatory understanding of the nature of performance indicators, primarily efficiency of activity. Otherwise, purposeful and efficient (effective and cost-effective) management of activities is almost impossible.

It so happened that the popular phrase "efficiency of activity" today does not have a clear, well-established definition, reflecting the meaning and clearly giving an image of efficiency of activity or management of activities. The conclusion is that the image of efficiency is not used in practice which is mathematically accurate and unquestionably accepted by the management community, and the existing terms differ in meaning.

Modern management theory has a wide range of methods for evaluating and analyzing performance. Their use provides an opportunity to study the structure of the organization (from top to bottom), the relationship between structural units, generalization of planning and implementation in the overall management strategy. Existing methodologies can be based on the Six Sigma strategy [11], activity based costing $(\mathrm{ABC})[12,13]$, total quality management (TQM) [14], economic value added (EVA) $[15,16]$, integrated strategic measurement [17] and the theory of constraints (TOC) [18]. These approaches cannot fully meet the enterprise's management needs, as they are mostly theoretical rather than practical, making it difficult to obtain an acceptable result.

However, it is already obvious that the use of a performance indicator (result and pro- cess) is a prerequisite for quality and successful management.

First, let's deal with the term. Efficiency today may mean the following: efficiency, economic efficiency (economy), timeliness, performance, profitability, etc.

For example, ISO 9000:2015 [19] defines efficiency as the ratio between the result achieved and the resources used. What is the effectiveness of this definition? We can assume that we are talking about economic efficiency: economic efficiency - the ratio of the cost of the results of production (products and/or services) and costs (labor and means of production). The semantic similarity of definitions in this case is obvious.

ISO 9000:2015 also gives a rather controversial definition of performance: the degree of implementation of the planned activities and the achievement of the planned results. It is a fairly correct definition, but it is necessary to give a different, we believe, more accurate, definition using the words "relationship" and "result" and take into account the time factor in the definition.

These definitions clearly show the incompleteness and variability of understanding of the terminology used, including in the recommendation documents (state standards). The absence of a single terminology apparatus leads to low controllability of activities, all the more complex. There are no uniform criteria for planning, achieving and evaluating results, nor for processes.

Thus, assessing the success of management is presently used in two entities: economic efficiency (economy) and performance, which are determined with fairly high accuracy, but a single basic integral indicator, taking into account both components, for management purposes is not applied, and it is necessary and simple enough. 


\section{The universal structure of a comprehensive management system}

The basis of any measurement is the method. Management can only be effective when the method of assessing it is appropriate to reality and is used as a real management tool.

Our proposed model of an integrated performance management system provides for such a practical tool based on the performance assessment method, as the variant of the development of the earned value method, which has been repeatedly tested in practice.

Figure 1 presents a conceptual model of the organizational structure of the resulting management structure and the interaction of the participants.

The concept of the organizational structure of an integrated system is based on the following assumptions: $\downarrow$ participants operate in the overall industry;

$\downarrow$ the scope and boundaries of participants' interactions are determined by the overlap of their activities;

$\checkmark$ the resulting efficiency triangle has parameters set in the interaction (content, duration, cost);

$\downarrow$ the quality is determined by the consumer's estimate/price of the result;

$\checkmark$ the resulting efficiency triangle is limited by the risk ring;

$\downarrow$ the risk ring does not go beyond the tops of the interaction triangle;

$\checkmark$ the resource triangle limits the ability to change the parameters of the result (content, duration, cost);

$\downarrow$ activity (process and result) estimates are determined by a comparison of planned and actual values of the parameters of the resulting efficiency triangle.

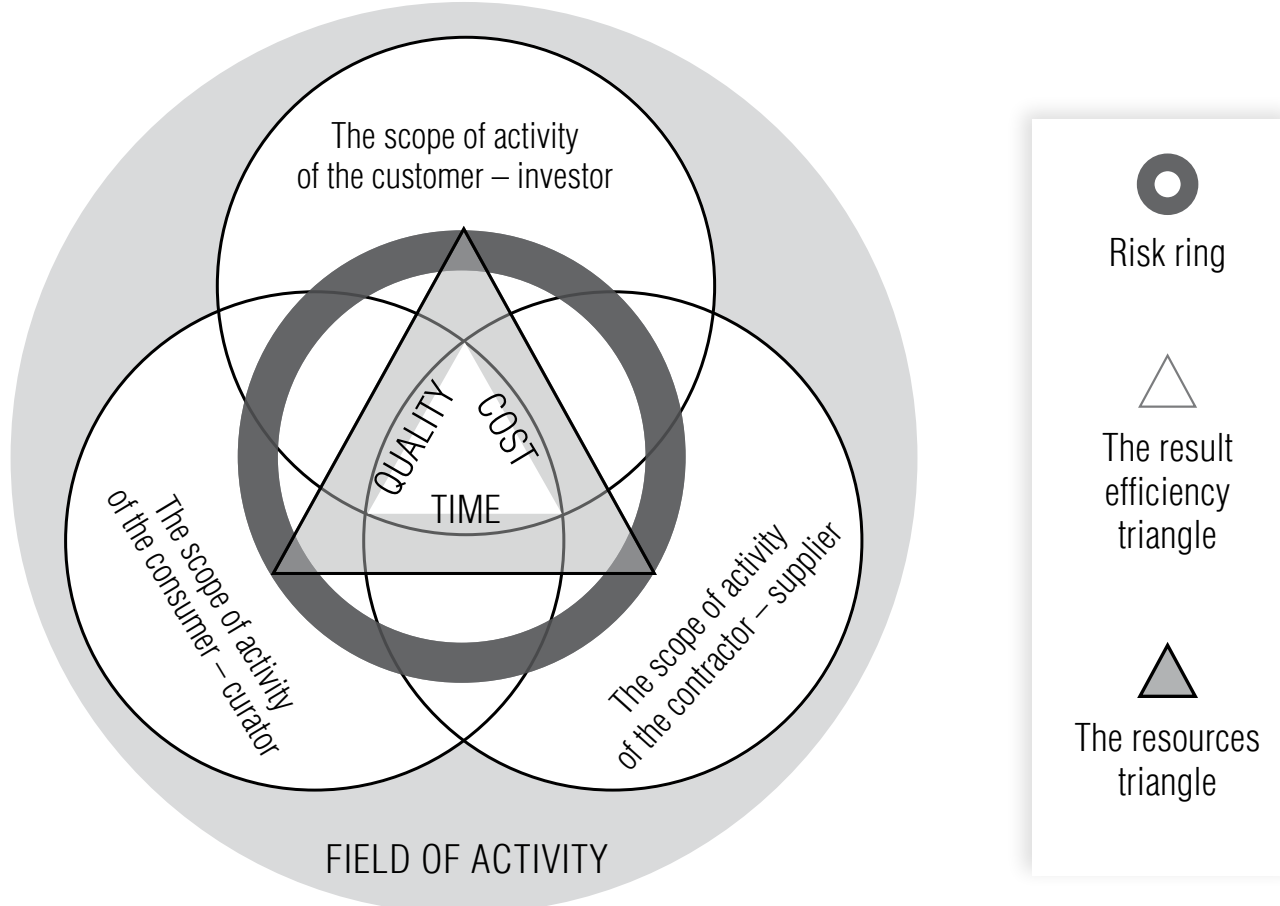

Fig. 1. Conceptual model of the interaction and resulting management structure 


\section{The image of efficiency and its use in a method for assessing the effectiveness of management}

A clear and mathematically defined image of efficiency is used to assess the performance assessment method by calculating performance and predicting performance indicators: Efficiency of activity is productivity based on efficiency (cost-effectiveness).

The performance assessment method, as well as the earned value method, measures $E A$ (efficiency of activity) at any given time in two parameters: $P$ (productivity) and $E$ (economy):

$$
E A=P \times E .
$$

This definition and formula for calculating efficiency allow for an integral assessment of management as a performance (taking into account the time factor) taking into account the resources spent on the actual result.

The performance assessment method allows you to assess the effectiveness of the performance both by result and by process, both employee or unit, and in general the company as a whole. This satisfies the main need of the manager - one numerical value to understand the situation at any implementation level of the task with an almost unlimited score (KPI, efficiency, etc.) and sub-tasks in the hierarchical structure of tasks.

This method makes it possible not only to evaluate the activity on a specific date, but also to predict the dynamics of indicators (efficiency, economy, profitability, timing of performance). Well-known approaches are applied: determining cost-effectiveness, as the ratio of the planned and actual cost of results; determining performance, as the ratio of actual and planned results taking into account the time factor when exceeding planned deadline.

However, despite the usual practice of using the earned value method abroad, in our country it does not find wide practical application in management. One reason is that users do not understand the image and meaning of calculated efficiency and find it difficult to calculate. We believe that the promotion of the performance assessment method (as a variant of the earned value method) will be facilitated by the visualization of the image of the activity and the system of its integral indicators, corresponding to the performance assessment method, if it is clearly presented in the form of an orthogonal system vectors at any given time (Figure 2). The direction of the actual efficiency of the activity vector is determined by the right-hand rule, by the shortest direction of rotation of the productivity vector to the efficiency vector.

Based on the formula and the definition of efficiency, let's present the efforts of doing business (efficiency and cost-effectiveness) as vectors aimed at achieving the result which is economically optimal. Then the efficiency of activity, as a result of the vector work of these vectors, is a vector orthogonal to the plane of the factor vectors (with direction according to the rule of the work of vectors) and numerically equal to the area of the rectangle built on these vectors:

$$
\overrightarrow{E A}=\vec{P} \times \vec{E}
$$

$E A$ (efficiency of activity) is a vector equal to that of two vectors: $P$ (productivity) and $E$ (efficiency). Efficiency can be imagined as an assessment of the usefulness of an activity by the size of the result (selling price, revenue, timeliness, volume of consumption, etc.) and in the direction (plus or minus).

Productivity is a vector (effort, ability, energy, aspiration, etc.) to achieve the planned (expected) result of activity.

Efficiency is a vector (effort, ability, energy, aspiration, etc.) to achieve optimal cost-effectiveness of the result of activity (optimal economic effect of activity).

So Figure 2 presents a way to determine (according to the rules of vector algebra) the 


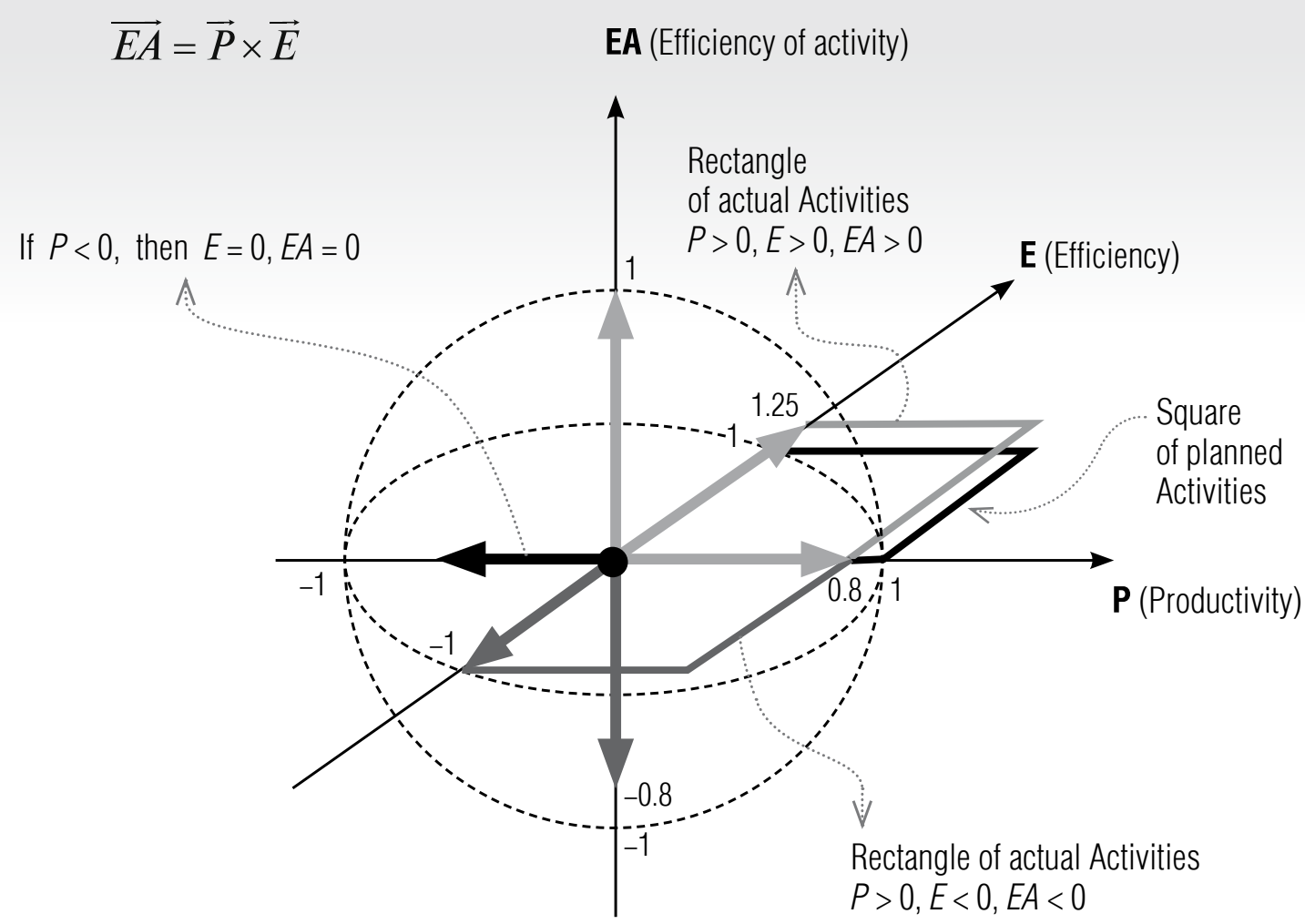

Fig. 2. Vector view of universal performance and management

assessment of the numerical value and direction of the efficiency vector in achieving the goal, as well as the problem of visibility of the image of efficiency and the activity itself and management of the process and result.

In this case, the productivity $(P)$ is calculated by the performance assessment method, as the ratio of the earned value $(E V)$ and the budget cost of the tasks planned for implementation $(P V)$, taking into account the ratio of planned and actual due date (SCT/ACT) according to the formula:

$$
P=\frac{E V}{V P} \times P S P I,
$$

where: $E V$ (Earned Value) is a well-developed volume (the planned cost of actually completed task volume; Budget Cost of Work Performed - BCWP);
$P V$ (Planned Value) is the budget cost of the planned task volume (the planned cost of the tasks planned for the project; Budget Cost of Work Scheduled - BCWS);

PSPI (Project Schedule Performance Index) is the index of project duration:

$$
P S P I=\frac{S C T}{A C T},
$$

where $S C T$ is the planned duration;

$A C T$ is the actual duration of the activity (if $A C T<S C T$, we take $P S P I=1$ for calculations).

Efficiency $(E)$ is calculated by the performance assessment method by comparing the cost of actual costs for the amount earned with the value of the earned value:

$$
E=1+\left(1-\frac{A C}{E V}\right) \times K p r .
$$


Profit Margin $(P M)$ can be calculated for commercial activity (when planning profits) under the efficiency formula.

In the formula (5) we accept:

$A C$ (Actual Cost) is the actual cost of the cost of the volume (Actual Cost of Work Performed, $A C W P$;

$K p r$ (Index Profit) is an index of transition from expense to profit (or specific planned expense for planned profit) that is accepted by an equal unit if profits are not planned. This is simply explained: if the activity is not aimed at making a profit, then the profit is not planned. In this case, both the profit and the expense directed to the profit, tend to zero (to the limit at a minimum).

The earnings transition index is defined as:

$$
K p r=\frac{P V}{P p r},
$$

where $P p r$ (planned profit)is the planned final profit at the end of the business.

The total universal performance formula (result and/or process) on cost-effectiveness or profit:

$$
E=\left[\frac{E V}{P V} \times P S P I\right] \times\left[1+\left(1-\frac{A C}{E V}\right) \times K p r\right] .
$$

In addition to the calculation formulas $(3,5$, 7) it should be noted that if the actual duration $(A C T)$ is less than the planned duration $(S C T)$, we take $P S P I=1$ for calculations; if one does not plan to make a profit, we'll take Kpr=1 for calculations.

\section{Practical application of the performance assessment method}

The performance assessment method is an advanced earned value method, the calculated formulas of which are added to determine corporate, inter-corporate and individual performance indicators: efficiency, efficiency, effi- ciency, profitability, timing, as well as forecasts used for management and motivation of activity.

In developing the performance assessment method, some problems have been solved and the shortcomings of the practical application of the earned value method have been eliminated:

There are many indicators of performance results, the assessments of which do not give accurate and unambiguous estimates and forecasts in general results and process of activity.

Solution: The cost of the earned volume is used as a universal measure of the proportion of each individual indicator (KPI) of a balanced system. The cost of the developed volumes is calculated through KPI in natural units. At the same time, both planned and actual KPIs should be specified in natural units of measurement. The integral volume of the task is equal to the amount of volumes mastered by KPI, which creates the ability to determine an integral assessment of performance (result or process) by one numerical value, including for tasks with multiple KPIs and many sub-tasks.

Estimates (indexes) do not take into account the time it takes to exceed the scheduled deadline.

Solution: The calculated formula includes a duration ratio equal to the planned duration to the actual $(S C T / A C T)$ applied when exceeding the planned period.

Reduce the reactive accuracy of the estimates to complete the task when used in the calculations of planned and actual data from the beginning of the task to the reporting date.

Solution: The calculation can be made at an arbitrary interval.

Formulas of the original earned value method do not allow us to calculate estimates on commercial profits (current and on completion) subject to profit planning.

Solution: the formula uses the unit expense index for profits. 
The management decision should be based on analysis and evaluation of information about the process and the interim result, with forecast of the effectiveness of the final result. Excessive or unstructured information inhibits decision-making, requiring additional time for analysis. Distorted or inaccurate information leads to errors and losses. To work with information, you need to choose the best activity management model to use a convenient performance assessment and forecasting system (results and process) where you can apply a combination of universal measurements to assessments: time and money [2326]. This will certainly give a multiple increase in overall productivity, lower costs (lean production) and increase profitability.

Taking for a specific weight of the result (KPI) the planned costs of its execution, it is easy to calculate the planned volume of the process in monetary units for each indicator at the time of assessment, as well as the planned volume of the result, with direct dependence of these volumes on the size of KPI in natural units of measurement, which, in our opinion, allows us to improve the reliability of information on the performance of these indicators.

This provides an opportunity to determine the volumes for each individual task and the enterprise as a whole, to calculate the performance, as the ratio of actual volume and planning based on the duration of execution, and to reduce to one certain value cost-effectiveness or profitability of the activity, and therefore calculate the efficiency of the activity as efficiency, taking into account economy or profitability.

\section{Conclusion}

Thus, managing the efficiency of the current activities, we get the necessary, planned results, provided that their achievement in force majeure does not go beyond restrictions on material resources and/or time. At the same time, universal, mutually transformable, com- plementary measures - time and money - are necessarily used for evaluations. This approach makes it possible to manage the process and the result purposefully.

Calculating integral indicators, primarily efficiency, is not an end in itself and allows for the use of actual assessments in the system of motivation and stimulation of activity, both personal and collective. In turn, the performance assessment method is used in the activity management system to determine deviations, which also makes it possible to make accurate and timely decisions in the management of process and outcome.

The simplicity and accessibility of the integrated performance assessment indicators at different levels of management enables participants to be involved in the management of different levels of work and perform different functions. This is fully in line with the opinion of the President of the Moscow branch of the Institute of Project Management V. Liberzon: “... an adequate project model (activity) should reflect reality so that it can be used for reliable planning and analysis in decision-making. Showing reality in practice means that:

$\downarrow$ element properties (processes, operations, functions, etc.) of the activity model include all the information that people use in planning and management;

$\downarrow$ information about resources and their assignments includes all the information that people use in planning and management;

$\downarrow$ resources are assigned in the same way as people do;

$\checkmark$ values are assigned in the same way as people do.” [27]

However, stimulating (forced) involvement in the management of joint activities of specific participants is not so much rational as motivational. Employee engagement and motivation is a key factor in the efficiency and management of activities. Motivation is a key task of HR management, for which a socially active 
employee should not be separated from the results of work by his own and his team and company. Thus, we are talking about a mechanism for understandable evaluation of work results, which is an important condition for the success of joint activities.

The practical application of the incentive and motivation system based on the indicators calculated by the performance assessment method [28] creates not only the economic growth of the enterprise, but also allows it to be protected in the event of external and/or internal risks, both managerial and production-technological, by reducing costs.
At the same time, the foregoing is part of a comprehensive business management system, and the performance assessment method can be applied in both corporate and inter-corporate joint management systems of various enterprises with different corporate cultures.

This approach enables purposeful and conscious management of the achievement of performance goals using the Balanced Scorecard system, which is simple enough if the enterprise has a system of planning, budgeting and management accounting of activities, and creates the prerequisites for the formation of intercorporate management systems.

\section{References}

1. Lytnev O.N. (2010) Strategic financial analysis using the DuPont model. Corporate finance management, no 3, pp. 158-171 (in Russian).

2. Redchenko K.I. (2003) Indicative disagreement: Balanced Scorecard and Tableau De Bord. Available at: http://www.e-xecutive.ru/knowledge/announce-ment/339363/?phrase_id=2806776 (accessed 17 March 2020) (in Russian).

3. Chiapello E., Lebas M. (1996) The Tableau de Bord, a French approach to management information. Presented at the 19th Annual Meeting of the European Accounting Association, Bergen, Norway, 2-4 May 1996.

4. Maisel L.S. (1992) Performance measurement. The balanced scorecard approach. Journal of Cost Management, Summer, pp. 45-62.

5. Adams C., Roberts P. (1993) You are what you measure. Manufacturing Europe. London: Sterling Publications, pp. 504-507.

6. Marr B. (2012) Key performance indicators. The 75 measures every manager needs to know. Harlow: Pearson.

7. Kaplan R.S., Norton D.P. (1996) Balanced Scorecard. Translating strategy into action. Harvard Business School Press.

8. Utenin V. (2011) The reasons for low efficiency of Russian companies. Corporate Management. Available at: https://www.cfin.ru/management/controlling/low_eff_reasons.shtml (accessed 17 March 2020) (in Russian).

9. Eskiev M.A., Aslahanova S.A., Beksultanova A.I. (2015) Effectiveness of the organization's management system. The main factors affecting the effectiveness. Young Scientist, no 23, pp. 689-692 (in Russian).

10. Lotakov I. (2019) Out of the shadows into the light flying. Russian business over the past 30 years through the eyes of its "parents" and "children". Available at: https://www.pwc.ru/ru/assets/knowledge-club/doing_business_in_ russia_rus_e-version.pdf (accessed 17 March 2020).

11.Kapterev A.V. (2012) Six Sigma business performance management concept and its application in Russia. Available at: https://gmpua.com/QM/Article/6Sigm/1/6sigma.pdf (accessed 12 January 2020) (in Russian).

12.Atamanov D.Yu. (2003) Cost apportionment using the traditional and activity based approaches. Journal of Marketing in Russia and Abroad, no 3, pp. 121-130 (in Russian).

13.Brimson J.A., Antos J. (1998) Driving value using activity based budgeting. New York: Wiley.

14.Khosrow D., ed. (1989) Quality control, robust design, and the Taguchi method. Pacific Grove, California: Wadsworth \& Brooks/Cole Advanced Books \& Software.

15.Ivashkovskaya I.V. (2004) Value based management: A challenge for Russian managers. Russian Management Journal, no 4, pp. 113-132 (in Russian).

16.Martin J.D., Petti J.W. (2000) Value based management: The corporate response to the shareholder revolution. Harvard Business School Press.

17.Gainullin A.I. (2015) About the specifics of the methodology of strategic enterprise management. Actual Directions of Scientific Research: From Theory to Practice, no 3 (5), pp. 377-380 (in Russian). 
18.Dettmer H.W. (1997) Goldratt's theory of constraints: A system approach to continuous improvement. Milwaukee, WI: ACQ Quality Press.

19.Standardinform (2015) GOST R ISO 9000-2015. Quality management systems. General terms and dictionary. Available at: http://docs.cntd.ru/document/1200124393 (accessed 11 January 2020).

20.Rach D.V. (2011) Method of graphical representation of indicators of the earned value. Project Management and Production Development, no (39), pp. 117-121 (in Russian).

21.Miloshevich D.Z. (2006) Project management toolkit. Moscow: AjTi; DMK Press (in Russian).

22.Levchenko A.Yu., Frei D.A. (2017) Problems of using the earned volume method for managing the cost of complex technological projects. Young Scientist, no 25, pp. 158-160 (in Russian).

23.Zuev B.P. (2014) Performance assessment method for evaluating performance in business management. Perm, PSU (in Russian).

24.Zuev B.P., Bulgakova I.N, Novosadov D.I. (2018) Integrated assessment of the practical effectiveness of management as the difficulty of achieving the goal. Proceedings of the International Scientific-Practical Conference on Methodology of Social and Humanitarian Sciences: Modern Context, Belgorod, 2018, part I, pp. 140-143 (in Russian).

25.Zuev M.B., Zuev B.P., Bulgakova I.N. (2019) The performance assessment method as a convenient tool for evaluating the effectiveness of activities (results and processes) in the field of management. Management in Russia and Abroad, no 5, pp. 11-18 (in Russian).

26.Zuev M.B., Zuev B.P., Bulgakova I.N. (2019) Modified earned value method for integrated efficiency assessment and forecasting of activities results in the field of management. Proceedings of the 1st International Scientific and Practical Conference "Project management: ideas, values, solutions”, Saint Petersburg, 2019, pp. 80-87 (in Russian).

27.Liberzon V. (2001) Project management. Management Today, no 5, pp. 2-8 (in Russian).

28.Zuev B.P. (2015) Performance assessment model. Integrated activity management system (practical model). Perm, PSU (in Russian).

\section{About the authors}

\section{Mikhail B. Zuev}

Adviser of the Director, Oil Component Ltd.

8, Heroes of Hassan Street, Perm 614000, Russia;

E-mail: m.zuev25@mail.ru

\section{Boris P. Zuev}

Technical Director of Performance Assessment Project, Oil Component Ltd., 8, Heroes of Hassan Street, Perm 614000, Russia;

E-mail: zuevboria@yandex.ru

\section{Irina N. Bulgakova}

D. Sci. (Econ.);

Associate Professor, Department of Mathematical Methods of Operations Research, Faculty of Applied Mathematics, Informatics and Mechanics, Voronezh State University, 1, University Square, Voronezh 394018, Russia;

E-mail: Bulgakova-IN@yandex.ru;

ORCID: 0000-0003-1779-5877 